\title{
Orthopedic Tissue Engineering
}

\section{Michael Detamore, Ph.D.}

Associate Professor of Chemical \& Petroleum Engineering

University of Kansas

March 9, 2010 


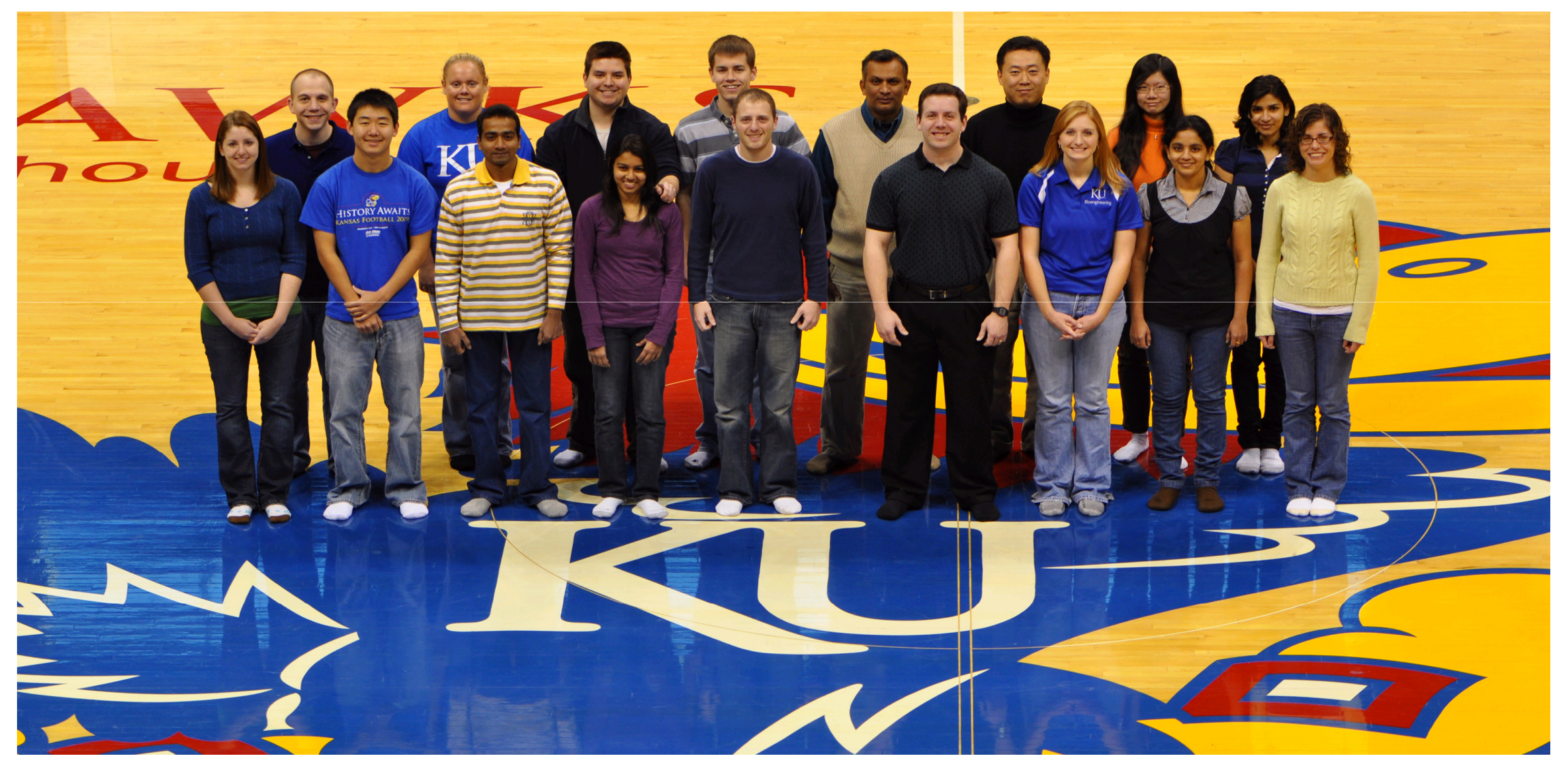


What does my group do?

- Tissue Engineering

- Biomaterials

- Stem Cells 


\section{Tissues of Interest}

- Temporomandibular Joint

- Intervertebral Disc

- Knee (osteochondral)*

- Cranium*

- Trachea*

- Liver ${ }^{*}$

- Cochlea* 


\section{Biomaterials Strategies}

- Microsphere-

based gradient scaffolds

- Colloidal gels

- Electrospinning

- IPN hydrogels 


\section{Biomaterials Strategies}

- Microspherebased gradient scaffolds

- Colloidal gels

- Electrospinning

- IPN hydrogels 


\section{Biomaterials Strategies}

- Microspherebased gradient scaffolds

- Colloidal gels

- Electrospinning

- IPN hydrogels 


\section{Biomaterials Strategies}

- Microsphere-based gradient scaffolds

- Colloidal gels

- Electrospinning

- IPN hydrogels
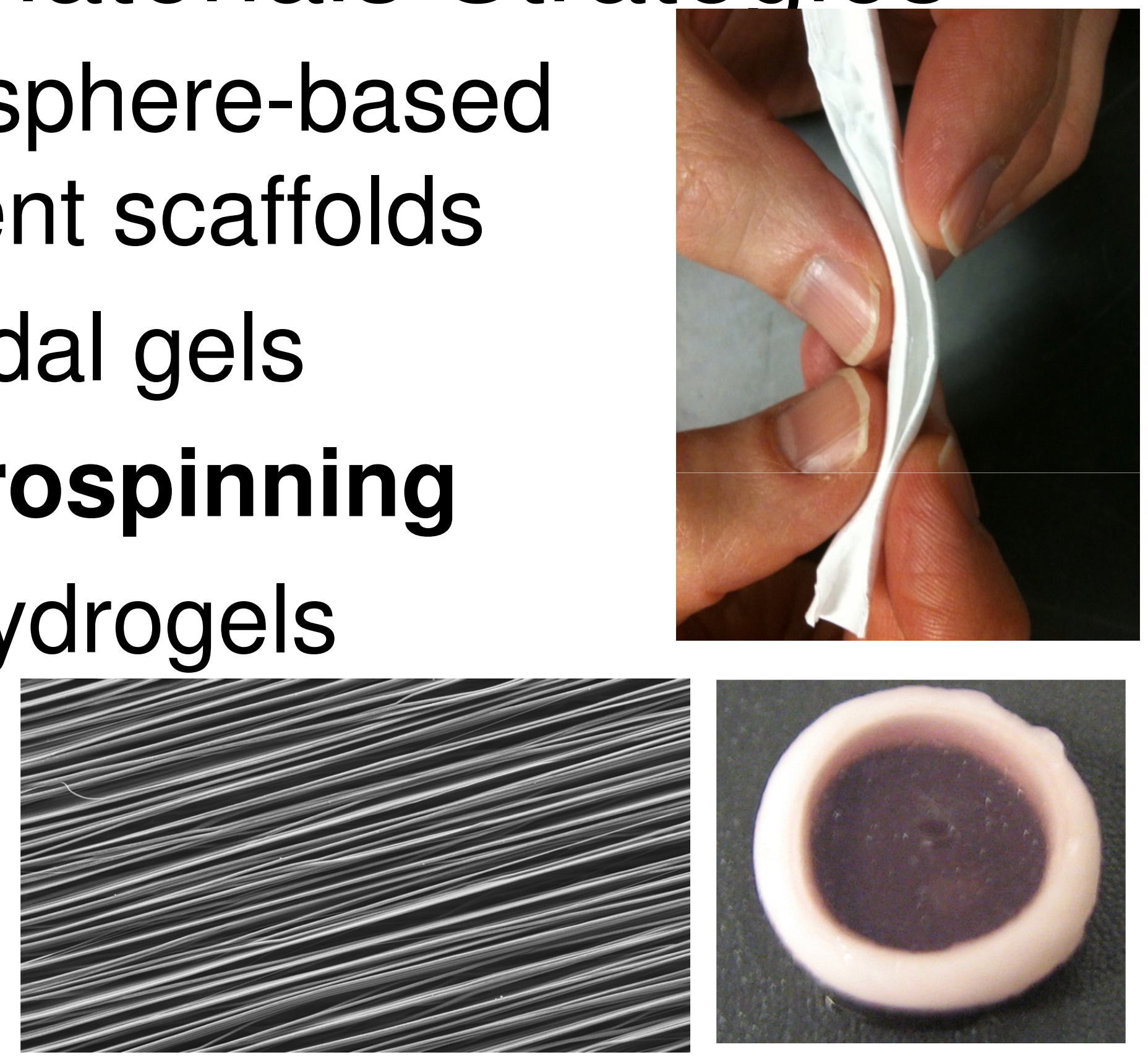


\section{Biomaterials Strategies}

- Microsphere-

based gradient scaffolds

- Colloidal gels

- Electrospinning

- IPN hydrogels 


\section{Umbilical cord stromal cells}

- Not cord blood, not HUVECs

- Combine with biomaterials

- Signaling strategies

- Comparisons to BMSCs 


\section{Collaborations \& Commercialization}

- Currently working with scientists, engineers, and surgeons

- Patents pending on gradient and IPN designs

- Interested in talking to entrepreneurs 


\section{Collaborations Across State Lines}

- UMKC Dental School (bone biology)

- Children's Mercy (ENT, orthopedics)

- Sinclair Research Center (in vivo)

- UM-Columbia (in vivo) 


\section{Biomaterials \& Tissue Engineering}

\section{Questions?}

\section{- ARTHRITIS FOUNDATION ${ }^{\oplus}$ \\ Take Control. We Can Help. ${ }^{\text {TM }}$}

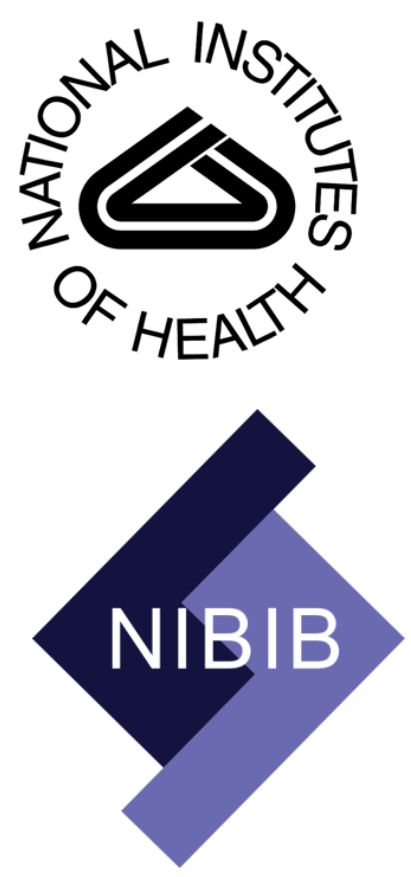

(1) Oral and

Maxillofacial

Surgery

Foundation

Leading the specialty through

support of research and education
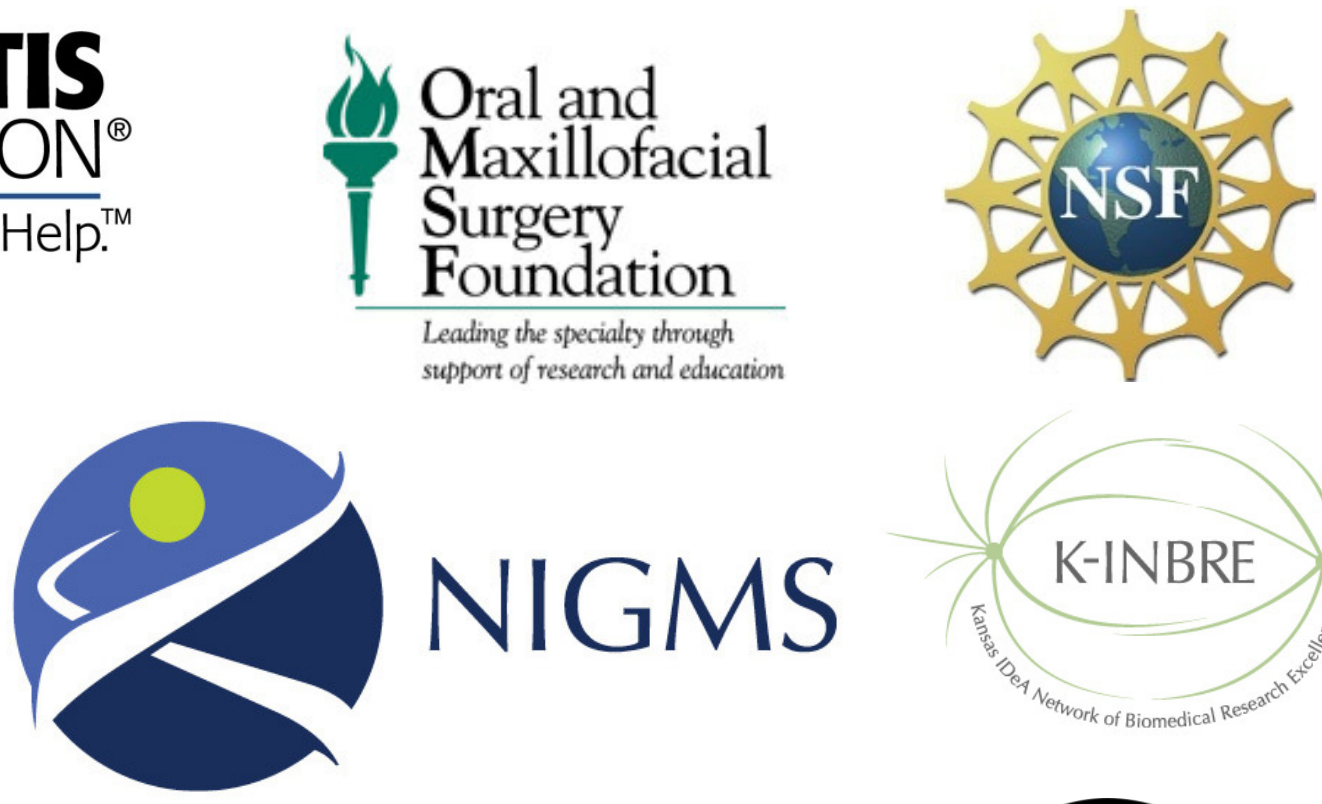

NIGMS

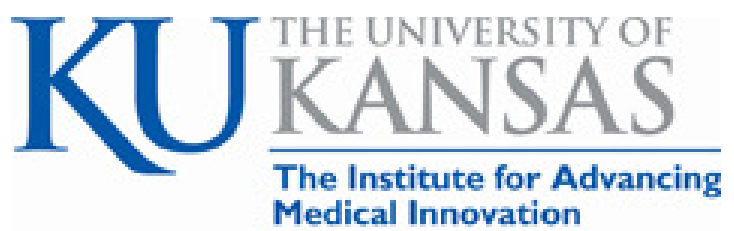

Medical Innovation and Craniofacial Research 